\title{
BMJ Open Incidence, comorbidity and mortality in patients with necrotising soft-tissue infections, 2005-2018: a Danish nationwide register-based cohort study
}

\author{
Morten Hedetoft (D) , ${ }^{1}$ Martin Bruun Madsen, ${ }^{2}$ Lærke Bruun Madsen, ${ }^{1}$ \\ Ole Hyldegaard ${ }^{1}$
}

To cite: Hedetoft $M$, Madsen MB, Madsen LB, et al. Incidence, comorbidity and mortality in patients with necrotising soft-tissue infections, 2005-2018: a Danish nationwide registerbased cohort study. BMJ Open 2020;10:e041302. doi:10.1136/ bmjopen-2020-041302

- Prepublication history and additional materials for this paper is available online. To view these files, please visit the journal online (http://dx.doi. org/10.1136/bmjopen-2020041302).

Received 04 June 2020 Revised 11 August 2020 Accepted 17 September 2020

Check for updates

(c) Author(s) (or their employer(s)) 2020. Re-use permitted under CC BY-NC. No commercial re-use. See rights and permissions. Published by BMJ.

${ }^{1}$ Department of Anaesthesia, Copenhagen University Hospital, Rigshospitalet, Copenhagen, Denmark

${ }^{2}$ Department of Intensive Care, 4131, Copenhagen University Hospital, Rigshospitalet, Copenhagen, Denmark

Correspondence to Dr Morten Hedetoft; morten.friis.fiskbaek.hedetoft@ regionh.dk

\section{ABSTRACT}

Objective To assess the incidence, comorbidities, treatment modalities and mortality in patients with necrotising soft-tissue infections (NSTIs) in Denmark. Design Nationwide population-based registry study. Setting Denmark.

Participants Danish residents with NSTI between 1 January 2005 and 31 August 2018.

Main outcome measure Incidence of disease per 100000 person/year and all-cause mortality at day 90 obtained from Danish National Patient Registry and the Danish Civil Registration System.

Results 1527 patients with NSTI were identified, yielding an incidence of 1.99 per 100000 person/year. All-cause 30-day, 90 -day and 1 -year mortality were $19.4 \%(95 \% \mathrm{Cl}$ $17.4 \%$ to $21.5 \%$ ), $25.2 \%$ (95\% Cl $23.1 \%$ to $27.5 \%$ ) and $30.4 \%$ (95\% Cl $28.0 \%$ to $32.8 \%$ ), respectively. Amputation occurred in $7 \%$ of the individuals. Diabetes was the most predominant comorbidity affecting $43 \%$ of the cohort, while $26 \%$ had no comorbidities. Higher age, female sex and increasing comorbidity index were found to be independent risk factors of mortality. Admission to highvolume hospitals was associated with improved survival (OR $0.59,95 \% \mathrm{Cl} 0.45$ to 0.77 ). Thirty-six per cent received hyperbaric oxygen therapy (HBOT) as an adjunctive therapy. No change in overall mortality was found over the studied time period.

Conclusion The present study found that in Denmark, the incidence of NSTI increased; mortality rates remained high and largely unaltered. Diabetes was the most common comorbidity, while higher age, female sex and increasing comorbidity index were associated to increased mortality. Survival was improved in those admitted to hospitals with more expertise in treating NSTI. In high-volume hospital, HBOT was associated with decreased odds for mortality.

\section{INTRODUCTION}

Necrotising soft-tissue infection (NSTI) is a severe disease associated with substantial morbidity and mortality. NSTI is characterised by rapidly progressing soft-tissue inflammation and necrosis. ${ }^{1}$ The infection can be either monomicrobial or polymicrobial, caused by numerous organisms but most
Strengths and limitations of this study

- All data linked on an individual level across registries with a substantial high follow-up rate.

- Nationwide cohort resulting in a precise estimate of national incidence, demographics and outcomes in contrast to observational studies.

- Inclusion of more than 1500 patients with necrotising soft-tissue infection across a 14-year time period: a relatively large sample size considering the rarity of disease.

- No clinical variables describing the severity of illness were obtainable from the registries, and so there may have been a subsequent lack of important factors that could have been built into the statistical models.

commonly by group A streptococcus. ${ }^{2}$ Immediate, aggressive and radical surgical debridement is key in the management of NSTI. Despite rigorous treatment, patients with NSTI have high mortality rates, risk of amputation and often have prolonged hospital and rehabilitation stays. Mortality rates can be markedly different $(6 \%-41 \%),{ }^{3-7}$ but a recent, large prospective multicentre study demonstrated a 90-day mortality of $18 \%$, which included the use of adjuvant therapies such as intravenous immunoglobulin and hyperbaric oxygen therapy (HBOT). ${ }^{2}$ Retrospective studies and pathophysiological reasoning have indicated that a delay to the first surgical debridement is associated with increased mortality. ${ }^{8-11}$ Surgery should be accompanied by broad-spectrum antibiotics and supportive intensive care, which taken together remain the standard of care in the treatment of NSTI.

HBOT has been advocated as adjunctive therapy to the multidisciplinary course of treatment for NSTI and has in retrospective studies been shown to reduce mortality, 
particularly in the most critically ill patients. ${ }^{12-14}$ As with most other treatment interventions in these patients, no randomised clinical trials investigating the effects of HBOT in these patients have been made. ${ }^{15}$ Only $1 \%$ of patients with NSTI in the USA received HBOT at specialised centres ${ }^{14}$ and although the use of HBOT is not universally accepted as a routine clinical treatment for this disease, ${ }^{16}{ }^{17}$ most retrospective clinical studies and larger database studies combined with a large body of preclinical data, may justify its current use as adjuvant therapy to surgery, antibiotic therapy and intensive care support. ${ }^{2-5}$ In Denmark, three HBOT-centres exits; of which two centres offer HBOT using monochambers but only one ICU-capable multicompartment chamber offers adjunctive routine HBOT for NSTI.

In Denmark, few major teaching hospitals receive patients with NSTI from other hospitals for multidisciplinary care. Of these, one receives patients from all parts of the country for centralised treatment using a multidisciplinary protocol, including HBOT. ${ }^{2}$ This should be of benefit, as an increased rate of survival has been shown in patients with NSTI who are treated in high-volume NSTI centres where expertise can be developed. ${ }^{18}$ However, as many patients with NSTI have septic shock and multiple organ failure, the delayed time taken for transportation to a centralised treatment hospital by air or road ambulance can pose a risk to life, and therefore, is not always feasible.

The epidemiology of NSTI in Denmark has never been fully described, and its nationwide incidence and mortality is unknown. Furthermore, it is not known how many patients are transferred after initial treatment to a centralised hospital for a multidisciplinary approach, or how many receive HBOT; only one centre offers HBOT to critically ill patients on a routine basis. The aim of this study was to evaluate NSTI incidence and mortality in Denmark with special attention to patients receiving centralised, multidisciplinary treatment, including adjuvant HBOT.

\section{MATERIAL AND METHODS \\ Setting}

This was a nationwide population-based registry study of patients diagnosed with NSTI between 1 January 2005 and 31 August 2018 in Denmark. Data were obtained from the Danish National Patient Registry (DNPR), ${ }^{19}$ the Danish Civil Registration System (CRS) ${ }^{20}$ and the Cause of Death Register (CDR). ${ }^{21}$ By law, public hospitals in Denmark are required to prospectively report data to these registries. All data were linked to each separate individual using a unique 10-digit number assigned to every Danish resident living in Denmark and non-Danish citizens patients treated in Denmark.

\section{Data collection}

All NSTI cases in Denmark were identified from the DNPR using International Classification of Diseases-10
(ICD-10) codes; M726 (necrotising fasciitis), M725A (necrotising fasciitis, before 2012), N498C (Fournier's gangrene) and A480 (gas gangrene). DNPR includes information on hospital contacts, procedures, diagnostic codes, admission and discharge dates on an individual level. To classify comorbidities, diagnoses were obtained from the DNPR, using the Charlson Comorbidity Index, a well-established classification including more than 17 medical conditions. ${ }^{22}$ A weighted Charlson Comorbidity Index was also used, as it has shown good discrimination when predicting in-hospital mortality. ${ }^{23}$ We included comorbidity diagnoses from 10 years prior to the NSTI diagnosis.

Data obtained from the CRS included information on sex, date of birth, vital status, date of death or emigration from Denmark. The CDR was used to gain information on cause of death on an individual level. In order to define a 'high-volume NSTI hospital', we identified the lowest number of NSTI patients treated yearly at one of the three major teaching hospitals in Denmark. In assessing procedures related to the NSTI diagnosis, we chose to include only data on surgical interventions, supportive modalities and procedures made within 7 days of NSTI diagnosis.

The study was written in compliance with the Reporting of Studies Conducted using Observational Routinely collected health Data statement ${ }^{24}$ (see online supplemental appendix 1). The ICD-10 codes used for extraction of comorbidities are found in the online supplemental appendix 2, and the Health Authorities Classification System (Danish; Sundhedsvæsenets Klassifikations System [SKS])-codes used for extraction of procedures (surgery and medical procedures/treatments) in online supplemental appendix 3 .

For those readers with a special interest, the quality of the DNPR and introduction to the Danish SKSclassification system has been reviewed by Schmidt et al. ${ }^{19}$

\section{Patient and public involvement}

No patients were involved in the design, implementation or dissemination of the results from the present study.

\section{Statistical analysis}

We expressed category characteristics and outcomes as absolute numbers (\%) and continuous data were reported as medians (IQR). Annual incidence was expressed as cases per 100000 persons per year. Mortality rates were presented as percentages with $95 \%$ CIs.

Comparisons were performed using Wilcoxon rank-sum test for quantitative data and Fisher's exact test for categorical data.

Unadjusted and adjusted multivariable logistic regression models were built to identify risk factors associated with increased mortality. All models included age, sex and weighted Charlson Comorbidity Index as covariates. Additionally, 'hospital category' and 'number of HBOTs' were included as covariates after showing significant association with survival in univariate analyses. $\mathrm{P}$ values were reported as exact values unless they were $<0.001$. 
NSTI: $2005-2018$

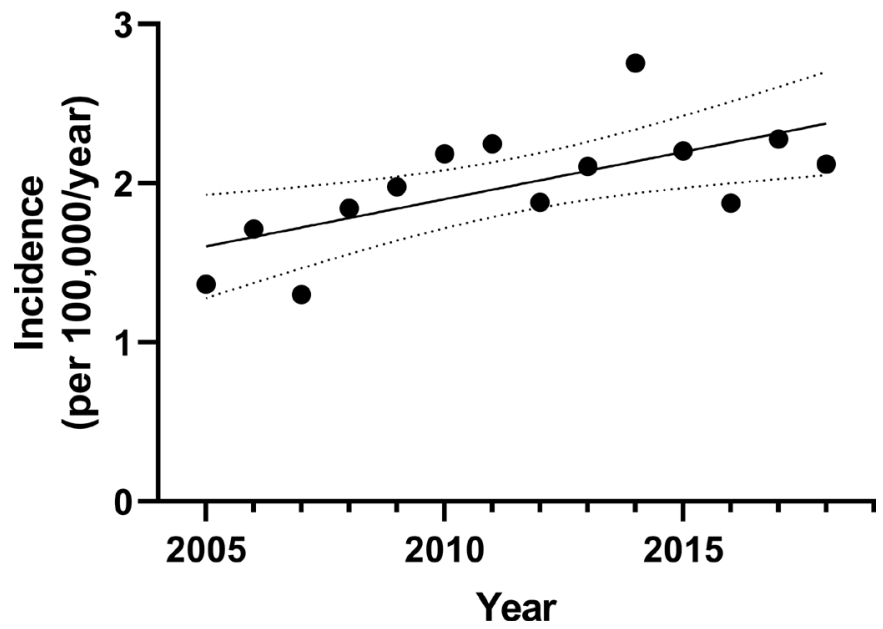

Figure 1 Yearly incidences of necrotising soft-tissue infection in Denmark. The solid line describes the trend by regression analysis; the dotted lines represent the 95\% Cls. NSTI, necrotising soft-tissue infection.

$\mathrm{P}$ values $<0.05$ were considered statistically significant. Patients who were lost to follow-up were excluded from the analyses. Statistical analyses were performed with RStudio V.1.0.153 (RStudio) and GraphPad Prism V.8.0.2 (GraphPad, La Jolla, California, USA).

\section{RESULTS}

A total of 1527 patients with NSTI were identified between 1 January 2005 and 31 August 2018, yielding a nationwide NSTI incidence of 1.99 per 100000 person/year (95\% CI 1.79 to 2.19$)$. Over the period of the study, a trend to an increased number of annual NSTI cases (0.06 per 100.000 person/year, $95 \%$ CI 0.02 to 0.10 ) was noted (figure 1).

Patient median age was 62 (IQR: 50-72), of which $63 \%$ were male. Of the 1527 patients included, 1303 (85\%) were registered with the diagnosis of necrotising fasciitis, $155(10 \%)$ with Fournier's gangrene and 362 (24\%) with gas gangrene. Two hundred and forty-four (16\%) patients were registered with more than one of the diagnoses. A total of $260(17 \%)$ had surgery within 4 weeks before the NSTI diagnosis. Characteristics including comorbidities and hospital category are presented in table 1. During the first 90 days after NSTI diagnosis, the median number of days alive and out of hospital were 55 (IQR: 10-76).

\section{Interventions and supportive modalities}

The majority (1506/1527; 99\%) of patients were admitted to an intensive care unit, with $86 \%$ being mechanically ventilated and $72 \%$ treated with vasopressor/inotrope (table 2). Two hundred and sixty-eight patients (18\%) were treated with renal-replacement therapy (at least one treatment with either hemodialysis or continuous renal-replacement therapy) and 554 (36\%) patients were treated with HBOT. These patients received their first HBOT after a median of 4.2 (IQR 2.1-6.2) hours
Table 1 Patients' characteristics

\begin{tabular}{lc}
\hline Patients ( $\mathrm{n}=1527)$ & \\
\hline Age (years) & $62(50-72)$ \\
\hline Sex, male & $966(63 \%)$ \\
\hline Comorbidities & $118(8 \%)$ \\
\hline Myocardial infarction & $227(15 \%)$ \\
\hline Congestive heart failure & $238(16 \%)$ \\
\hline Peripheral vascular disease & $235(15 \%)$ \\
\hline Cerebrovascular disease & $53(4 \%)$ \\
\hline Dementia & $283(19 \%)$ \\
\hline Chronic pulmonary disease & $87(6 \%)$ \\
\hline Rheumatological disease & $116(8 \%)$ \\
\hline Peptic ulcer disease & $126(8 \%)$ \\
\hline Mild liver disease & $63(4 \%)$ \\
\hline Moderate or severe liver disease & $431(28 \%)$ \\
\hline Diabetes without chronic complications & $228(15 \%)$ \\
\hline Diabetes with chronic compilations & $40(3 \%)$ \\
\hline Hemiplegia or paraplegia & $201(13 \%)$ \\
\hline Renal disease & $330(22 \%)$ \\
\hline Cancer (any malignancy) & $80(5 \%)$ \\
\hline Metastatic solid tumour & $11(1 \%)$ \\
\hline HIV/AIDS & $1(0-2)$ \\
\hline Charlson score & \\
\hline Charlson comorbidity index & \\
\hline
\end{tabular}

\begin{tabular}{|cr|}
\hline 0 & $398(26 \%)$ \\
\hline $1-2$ & $759(50 \%)$ \\
\hline $3-4$ & $286(19 \%)$ \\
\hline$\geq 5$ & $84(6 \%)$ \\
\hline Weighted Charlson score & $2(0-4)$ \\
\hline Weighted Charlson comorbidity index & \\
\hline 0 & $398(26 \%)$ \\
\hline $1-2$ & $506(33 \%)$ \\
\hline $3-4$ & $330(22 \%)$ \\
\hline$\geq 5$ & $293(19 \%)$ \\
\hline Hospital category & \\
\hline Low volume (<8 NSTI/year) & $419(27 \%)$ \\
\hline High volume ( $\geq 8$ NSTI/year) & $1108(73 \%)$ \\
\hline Period (year) & $694(45 \%)$ \\
\hline $2005-2011$ & $833(55 \%)$ \\
\hline 2012-2018 & \\
\hline Other & $472(31 \%)$ \\
\hline Septic shock & $260(17 \%)$ \\
\hline Surgery <4 weeks prior to diagnosis of NSTI & \\
\hline
\end{tabular}

Data are presented as $\mathrm{n}(\%)$ or median (IQR). Comorbidity diagnoses from 10 years prior until NSTI diagnosis. Each comorbidity was defined as by the Charlson conditions (ICD-10 diagnoses in online supplemental appendix 2). Septic shock was defined as the ICD-10 diagnosis 'septic shock' or 'sepsis' and a concurrent diagnosis of inotropes (diagnoses and supportive modalities in online supplemental appendix 3).

${ }^{*}$ Defined as the lowest number of NSTI cases annually treated at one of the three main teaching hospitals in Denmark.

ICD-10, International Classification of Diseases-10; NSTI, necrotising soft-tissue infection. 


\begin{tabular}{ll}
\hline Table 2 Interventions in patients with NSTI \\
Surgery \\
Amputations & $111(7.7 \%)$ \\
No of surgical interventions & $6(3-10)$ \\
Supportive modalities & $1506(99 \%)$ \\
Admission to intensive care unit & $1317(86 \%)$ \\
Mechanical ventilation & $1095(72 \%)$ \\
Use of vasopressor/inotrope & $268(18 \%)$ \\
Renal-replacement therapy, at least one \\
treatment \\
HBOT, at any time & $554(36 \%)$ \\
Hours from diagnosis to first HBOT & $4.2(2.1-6.2)$ \\
No of HBOT & $3(2-3)$ \\
$\geq 2$ HBOT within 24 hours & $252(45 \%)$ \\
\hline
\end{tabular}

Procedures/interventions within 7 days from NSTI diagnosis. Data are presented as $\mathrm{n}(\%)$ or median (IQR).

HBOT, hyperbaric oxygen therapy; NSTI, necrotising soft-tissue infection.

from diagnosis at the admitting hospital. They received a median of three HBOT sessions (IQR 2-3), and 45\% received two or more HBOT sessions within 24 hours after arrival. The remaining 974 (64\%) patients did not receive HBOT as a treatment modality for their NSTI. Among those patients who were referred to a HBOT-capable hospital, the annual percentage of HBOT-treated patients varied from $56 \%$ to $82 \%$ (lowest 2006, highest 2015).

A total of $111(7 \%)$ patients underwent at least one type of amputation within 7 days of NSTI diagnosis. Amputation of the upper leg was the most common, and was seen in $73(5 \%)$ patients, followed by amputation of the lower leg $(\mathrm{n}=18,1 \%)$, upper $\operatorname{arm}(\mathrm{n}=11,<1 \%)$, penis $(\mathrm{n}=6$, $<1 \%)$, lower arm $(\mathrm{n}=3,<1 \%)$, foot $(\mathrm{n}=3,<1 \%)$ and hand $(\mathrm{n}=1,<1 \%)$. Four patients underwent more than one type of amputation.

\section{Mortality}

Six patients were lost to follow-up at day 90 , resulting in a 99.6\% follow-up rate. These patients were excluded from the survival analyses. In total, 295 patients died within 30 days of diagnosis $(19.4 \%, 95 \%$ CI $17.4 \%$ to $21.5 \%)$ and 384 within 90 days $(25.2 \%, 95 \%$ CI $23.1 \%$ to $27.5 \%)$ (figure 2). As patients who entered the study in 2018 have not been studied for a full year when the study was ended, these patients were excluded from assessment of 1-year mortality. Of the 1429 individuals enrolled from 2005 to 2017 , 1-year mortality was $30.4 \%$ (95\% CI $28.0 \%$ to $32.8 \%$ ). Patients who did not survive until day 30 died after a median of 4 days (IQR: 1-11). Patients with no previous comorbidities had a 30-day, 90-day and 1-year mortality rate of $11.4 \%$ (95\% CI $8.5 \%$ to $15.0 \%$ ), $13.7 \%$ (95\% CI $10.5 \%$ to $17.5 \%$ ) and $15.4 \%$ (95\% CI $11.8 \%$ to $19.5 \%$ ), respectively. Mortality rates by comorbidity groups are presented in table 3 .

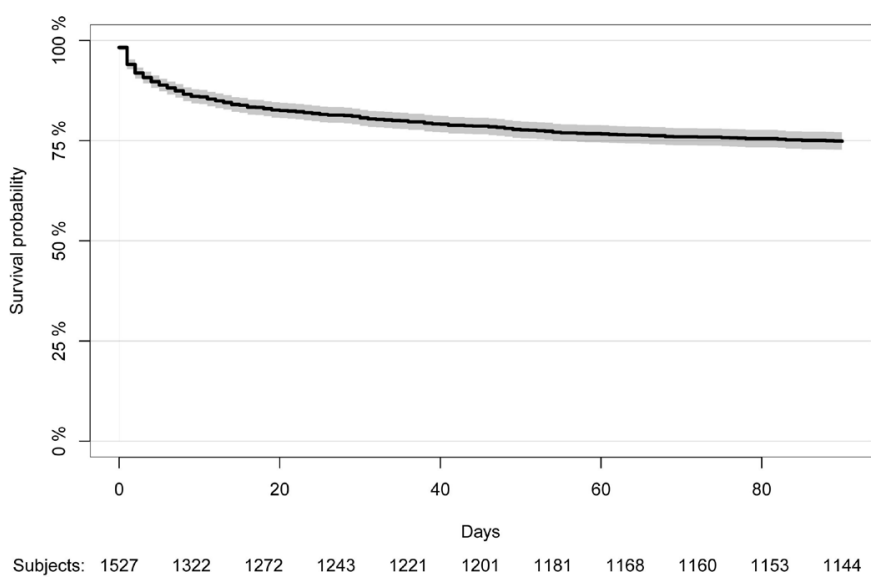

Figure 2 Survival curve for patients with necrotising softtissue infection. The solid line represents the survival curve. The grey area represents the $95 \% \mathrm{Cl}$. The survival curve was censored at day 90.

Multivariable logistic regression models showed that factors associated with an increased 90-day mortality were increasing age, female sex, increased weighted Charlson index and treatment exclusively at low-volume NSTI hospitals (table 4). Receiving two or more HBOT sessions within 24 hours from diagnosis was not significant in either unadjusted or adjusted analyses. In unadjusted analysis, patients receiving three HBOT sessions had a significantly decreased risk of death $(\mathrm{p}=0.03)$ compared with other HBOT-treated patients. However, this was not significant after adjustment for age, sex and comorbidities $(\mathrm{p}=0.07)$. No improved overall survival was found from 2012 to 2018 compared with 2005-2011 (table 4).

Three high-volume NSTI hospitals ( $>8$ NSTI cases/ annually) were identified. Patients treated at one highvolume NSTI hospital offering HBOT as an adjunct ( $\mathrm{n}=859$, including 554 HBOT-treated), had significant decreased risk of death compared with patients treated at one high-volume, non-HBOT hospital $(\mathrm{n}=125)$ with ORs for 30-day mortality and 90-day mortality of 0.54 (95\% CI 0.33 to $0.91, \mathrm{p}=0.02$ ) and of 0.61 (95\% CI 0.39 to 0.97 , $\mathrm{p}=0.03$ ), respectively. No differences were found in age, sex or weighted comorbidity index between these highvolume hospitals $(\mathrm{p}=0.18, \mathrm{p}=0.77$ and $\mathrm{p}=0.06$, respectively). The 30-day non-survivors died after a median of 4 and 5 days in these two hospital categories.

HBOT-treated NSTI patients had a 30-day mortality of $7.4 \%$ (95\% CI $5.4 \%$ to $9.9 \%$ ) and a 90-day mortality of 13.9 (95\% CI 11.1 to 17.1). 'Necrotising fasciitis' (M726/725) was the single most reported cause of death at day 90 $(\mathrm{n}=84)$, followed by 'other fibroblastic disorders' (M728) $(n=16)$ and 'sepsis, unspecified organism' (A419) (n=13).

\section{DISCUSSION}

The Danish registries that were used in the present study are unique, in that they can link clinical information to an individual level. Using data drawn from these databases, we studied patients with NSTI in Denmark 
Table 3 All-cause mortality across severity of comorbidity

\begin{tabular}{llll}
$\begin{array}{l}\text { Weighted } \\
\text { Charlson Index }\end{array}$ & 30-day mortality & 90-day mortality & 1-year mortality* \\
\hline 0 & $11.4 \%(95 \% \mathrm{Cl} 8.5 \%$ to $15.0 \%)$ & $13.7 \%(95 \% \mathrm{Cl} 11.6 \%$ to $18.9 \%)$ & $15.4 \%(95 \% \mathrm{Cl} 11.8 \%$ to $19.5 \%)$ \\
$1-2$ & $20.6 \%(95 \% \mathrm{Cl} 17.1 \%$ to $24.4 \%)$ & $26.3 \%(95 \% \mathrm{Cl} 22.5 \%$ to $30.4 \%)$ & $31.6 \%(95 \% \mathrm{Cl} 27.4 \%$ to $36.1 \%)$ \\
$3-4$ & $25.8 \%(95 \% \mathrm{Cl} 21.1 \%$ to $30.8 \%)$ & $30.6 \%(95 \% \mathrm{Cl} 25.7 \%$ to $35.9 \%)$ & $37.3 \%(95 \% \mathrm{Cl} 31.9 \%$ to $42.9 \%)$ \\
$\geq 5$ & $20.9 \%(95 \% \mathrm{Cl} 16.4 \%$ to $26.0 \%)$ & $32.9 \%(95 \% \mathrm{Cl} 27.5 \%$ to $38.6 \%)$ & $40.4 \%(95 \% \mathrm{Cl} 34.6 \%$ to $46.4 \%)$ \\
\hline
\end{tabular}

*Patients enrolled 2005-2017 ( $n=1429)$.

between 1 January 2005 and 31 August 2018. We found a mean incidence of NSTI of 1.99 per 100000 inhabitants / year; in a study from Northern Thailand, incidence rates as high as 15.5 per 100000 inhabitants/year have been observed, ${ }^{25}$ but the present results are similar to those of New Zealand (1.69 per 100000 inhabitants/year) ${ }^{26}$ and Western Norway (3.0 per 100000$).^{27}$

During the observation period of approximately 14 years, the incidence of NSTI appeared to increase. Numerous factors may have influenced this finding, including increased awareness of $\mathrm{NSTI}^{28}$ and changes in the practice of registering diagnoses. However, the trend could represent a true increase in disease incidence, similar to that observed in the USA and New Zealand. ${ }^{26}{ }^{29}$ We found an all-cause 30-day, 90-day and 1-year mortality rate of $19 \%, 25 \%$ and $30 \%$, respectively. In other retrospective studies, mortality varies considerably, with values as high as $41 \% .^{7}$ The 30 -day rate found in the present study is similar to the 28-day mortality rate of $18 \%$ reported in a recent French registry study ${ }^{18}$ but is substantially higher than an overall mortality of 5\%-10\% reported in a registry study including more than 45913 NSTI patients. ${ }^{14}$ NSTI is rare and no diagnostic criteria exist; in general, the diagnosis is made by the surgeon

\begin{tabular}{|c|c|c|c|c|}
\hline Patients $(n=1521)$ & Crude OR $(95 \% \mathrm{Cl})$ & $P$ value & Adjusted OR (95\% Cl) & $P$ value \\
\hline Age (years) & 1.06 (1.05 to 1.08$)$ & $<0.001$ & 1.06 (1.05 to 1.07$)$ & $<0.001$ \\
\hline \multicolumn{5}{|c|}{ Weighted Charlson comorbidity index } \\
\hline 0 & 1 (Ref.) & & 1 (Ref.) & \\
\hline$\geq 5$ & $3.10(2.14$ to 4.55$)$ & $<0.001$ & 1.96 (1.31 to 2.96$)$ & 0.001 \\
\hline \multicolumn{5}{|l|}{ Hospital category* } \\
\hline$<8 \mathrm{NSTI} /$ year & 1 (Ref.) & & 1 (Ref.) & \\
\hline$\geq 8 \mathrm{NSTI} /$ year & 0.48 (0.38 to 0.61$)$ & $<0.001$ & 0.59 (0.45 to 0.77$)$ & $<0.001$ \\
\hline \multicolumn{5}{|c|}{ HBOT treated individuals $(n=554)$} \\
\hline \multicolumn{5}{|l|}{ No of HBOT, total } \\
\hline 1 & 1 (Ref.) & & 1 (Ref.) & \\
\hline 2 & $0.72(0.37$ to 1.41$)$ & 0.34 & $0.83(0.38$ to 1.80$)$ & 0.64 \\
\hline 3 & $0.49(0.25$ to 0.94$)$ & 0.03 & $0.49(0.22$ to 1.05$)$ & 0.07 \\
\hline \multicolumn{5}{|c|}{ Sessions within 24 hours } \\
\hline$\geq 2$ HBOT & 1 (Ref.) & & 1 (Ref.) & \\
\hline$<2$ HBOT & 1.45 (0.89 to 2.41$)$ & 0.14 & 1.37 (0.73 to 2.59$)$ & 0.34 \\
\hline
\end{tabular}

Multivariable logistic regression model adjusted for age, sex and weighted Charlson Comorbidity Index. Six $(n=6)$ patients were lost to follow-up and were not included in the analyses.

*Defined as the lowest number of NSTI cases annually treated at one of the three main teaching hospitals in Denmark.

HBOT, hyperbaric oxygen therapy; NSTI, necrotising soft-tissue infection. 
during surgery. CT has demonstrated a sensitivity of $89 \%$ and specificity of $93 \%$ in diagnostic accuracy ${ }^{30}$ and may as well be required in visualisation of portal of entry and extension of infection. ${ }^{31} 32$ The Laboratory Risk Indicator for Necrotising Fasciitis (LRINEC) has demonstrated varying performances across clinical studies suggesting that the LRINEC should not be used to rule out NSTI. ${ }^{30}{ }^{33-35}$ Different classifications are based on location, eponyms and aetiology. The noticeable difference in mortality among studies could reflect the heterogeneity of NSTI patients, but also the complexity of diagnosing NSTI. In our study, $16 \%$ of patients had more than one of three codes registered, confirming this complexity. Factors independently associated with higher mortality at day 90 were older age, female sex, increasing weighted Charlson Index and treatment exclusively at low-volume NSTI hospitals. Increasing age has been reported as a risk factor of death in numerous of studies, but conflicting evidence exists as to whether female sex is an independent risk factor or not. ${ }^{218}$

Approximately $30 \%$ of patients in the present cohort had septic shock; this value is lower than reported recently in a prospective observational study including Scandinavian high-volume hospitals, where $50 \%$ had septic shock. ${ }^{2}$ Data from the DNPR has shown positive predictive values of $69 \%-82 \%$ for septic shock diagnoses, which might explain this difference. ${ }^{36}$ However, it is possible that as the hospitals in the Scandinavian study were high volume and took in a disproportionately large number of severe cases (including septic shock, eg), the findings are not directly comparable; the present cohort included all cases, including patients that were not transferred to specialised centres and thereby represents the overall nationwide incidence. Additional selection bias for severe cases might also be imposed by transport time, as the most severe cases may not be transferred to specialised centres possibly due to transportation constituting a risk in itself. Despite declining mortality rates among patients with sepsis in general, ${ }^{3738}$ NSTI still remains a substantial risk of death. In accordance with existing literature ${ }^{18}$ we did not find any significant improvement in NSTI survival over the years studied.

Admission to hospitals managing $\geq 8$ NSTI cases annually in this cohort was associated with lower mortality. Admission to hospitals ( $\geq 3$ NSTI patients per year) was also associated with lower mortality in France. ${ }^{18}$ These findings might reflect a greater level of expertise in high-volume hospitals, which are also often able to offer immediate access to operating theatres and intensive care units with experienced professionals, including microbiologists, infectious disease specialists and dermatologists, at all hours. In deriving our definition of a high-volume NSTI hospital in Denmark, we used a cut-off value that represented the lowest number of NSTI cases treated at one of the three major teaching hospitals in Denmark. These hospitals are the most highly specialised in the country, with optimal clinical care including a multidisciplinary approach in the treatment of NSTI. ${ }^{16}$
Although diabetes may remain a significant burden of disease, it has not been associated with higher mortality rates in NSTI. ${ }^{2}$ Diabetes was the most common comorbidity, affecting $43 \%$ of patients, followed by $22 \%$ with cancer and $19 \%$ with chronic pulmonary disease. This varied considerably in comparison to a large French registry study where $29 \%$ of patients had diabetes and $9 \%$ had cancer. ${ }^{18}$ The values from our study are not extraordinarily high, however, the proportion of patients with diabetes affected by NSTI has been reported in previous studies to be as high as $71 \%{ }^{8}$ We used the Charlson Comorbidity Index ${ }^{22}$ to address burden of diseases, as it is one of the most frequently used comorbidity indexes, especially in survival analysis of cancer. ${ }^{39-41}$ However, the index also predicts 30-day and 1-year mortality in intensive care patients, which the results from the present cohort is consistent with. ${ }^{42}$ For ease of comparison between studies, we reported the Quan's weighted Charlson comorbidity score, as it is increasingly reported as the only comorbidity variable. ${ }^{23} 43$

A $98 \%$ positive predictive value has been shown for the Charlson's conditions obtained from the DNPR. ${ }^{44}$

Surprisingly, $26 \%$ of the patients $(n=398)$ did not have any comorbidities at time of NSTI diagnosis. Validation of the Charlson Comorbidity Index showed an in-hospital mortality of $0.4 \%-2.6 \%$ in patients with a comorbidity score of 0 . This contrasts with an $11 \%$ 30-day mortality among patients with no comorbidities in the present cohort and highlights the severity of the NSTI even for those without pre-existing disease. Recent surgical interventions do pose a risk factor of developing NSTI $^{1}$ and nearly one-fifth $(17 \%)$ of the cohort had had surgery within 4 weeks before NSTI was diagnosed.

An improved 30-day and 90-day survival in hospitals offering HBOT as an adjunct to the multidisciplinary treatment was noted. However, these results should be interpreted cautiously due to missing confounders, such as clinical variables and potentially different treatment modalities across hospitals. Mortality among HBOTtreated individuals was noticeably reduced compared with those who did not receive HBOT. This could indicate that HBOT provides a 'real' treatment effect, but the difference is marked and could accentuate a selection bias based on which patients are offered HBOT as an adjunct. Fifty-six to eighty-two percentage of the patients who were admitted to a HBOT capable hospital received HBOT. Presumably, some may have been in such critical haemodynamic condition were in-hospital transportation to HBOT were deemed unachievable, thereby indicating that the HBOTtreated patients represent a selected cohort. Although access to HBOT is limited, the early transfer of patients from a primary hospital to a larger, specialised referral centre did not seem to worsen outcome of patients with suspected or confirmed NSTI. ${ }^{18} 4546$ Current recommendations based largely on retrospective clinical studies and preclinical evidence recommend six to seven HBOT sessions within the first 72 hours from admission. ${ }^{47-49}$ Our data found that a median number of 3 sessions of 
HBOT were given in this cohort; this could be looked on as undertreatment. However, no randomised trials exist that can either recommend or refute the use of HBOT on NSTI patients. ${ }^{15}$

Our study has some limitations: first, we did not confirm the NSTI diagnoses retrieved from the DNPR by medical records; second, treatment modalities may vary among hospitals, potentially affecting mortality rates differently; third, in contrast to prospective observational studies, no clinical variables describing the severity of illness (eg, Simplified Acute Physiology Score III etc) were obtainable from the registries, and so there may have been a subsequent lack of important factors that could have been built into the statistical models. The strengths of the study were that all patients with a diagnosis of NSTI nationwide were included, resulting in a precise estimate of the national incidence. The diagnoses for Charlson comorbidities, as well as the codes describing the supportive modalities have shown generally high positive predictive values when obtained from the DNPR. ${ }^{19}$ Moreover, the present study included data from a large sample size derived over approximately 14 years with a high follow-up rate.

In conclusion, this nationwide study showed that incidence of NSTI is increasing, although mortality rates remain high and largely unaltered. Age, female sex and increasing comorbidities were statistically significant independent factors associated with increased mortality. Admission to a high-volume NSTI hospital was associated with lower mortality. In centres treating $>8$ patients per year, HBOT was associated with decreased odds for mortality.

Contributors Study planning (MH, MBM, LBM and $\mathrm{OH}$ ), data analysis ( $\mathrm{MH}$ and $\mathrm{MBM}$ ), results interpretation ( $\mathrm{MH}, \mathrm{MBM}, \mathrm{LBM}$ and $\mathrm{OH}$ ), drafting manuscript ( $\mathrm{MH}$ and $\mathrm{OH})$, revision and approval of final version of manuscript ( $\mathrm{MH}, \mathrm{MBM}, \mathrm{LBM}$ and $\mathrm{OH})$. The corresponding author attests that all listed authors meet authorship criteria and that no others meeting the criteria have been omitted. Corresponding author serves as guarantor for the present study.

Funding This work was supported by 'Copenhagen University Hospital (Rigshospitalet) Research Grant' (grant number R167-A7352-B3897), which included a research fellowship for $\mathrm{MH}$. Moreover, the study was supported by the projects of PERMIT (grant number 8113-00009B) funded by Innovation Fund Denmark and EU Horizon 2020 under the frame of ERA PerMed (project 2018-151) and PERAID (grant number 8114-00005B) funded by Innovation Fund Denmark and Nordforsk (project 90456).

Disclaimer No funders had any role in the design, conduct, collection, analysis, and interpretation of the data. Nor in the preparation, approval or submission of the manuscript.

Competing interests None declared.

Patient consent for publication Not required.

Ethics approval The present study was approved by The Danish Data Protection Agency (P-2019-153) and the Danish Health Data Authority (FSEID-0004419). According to Danish law, the use of observational data from approved registries does not require ethical approval or informed consent

Provenance and peer review Not commissioned; externally peer reviewed.

Data availability statement Data may be obtained from a third party and are not publicly available. Data not available for sharing. For information on how to access to the Danish National Patient Registry, the Danish Civil Registration System and the Cause of Death Register, follow the instructions at https://sundhedsdatastyrelsen. $\mathrm{dk} /$ forskerservice.
Supplemental material This content has been supplied by the author(s). It has not been vetted by BMJ Publishing Group Limited (BMJ) and may not have been peer-reviewed. Any opinions or recommendations discussed are solely those of the author(s) and are not endorsed by BMJ. BMJ disclaims all liability and responsibility arising from any reliance placed on the content. Where the content includes any translated material, BMJ does not warrant the accuracy and reliability of the translations (including but not limited to local regulations, clinical guidelines, terminology, drug names and drug dosages), and is not responsible for any error and/or omissions arising from translation and adaptation or otherwise.

Open access This is an open access article distributed in accordance with the Creative Commons Attribution Non Commercial (CC BY-NC 4.0) license, which permits others to distribute, remix, adapt, build upon this work non-commercially, and license their derivative works on different terms, provided the original work is properly cited, appropriate credit is given, any changes made indicated, and the use is non-commercial. See: http://creativecommons.org/licenses/by-nc/4.0/.

ORCID iD

Morten Hedetoft http://orcid.org/0000-0002-2606-8041

\section{REFERENCES}

1 Stevens DL, Bryant AE. Necrotizing soft-tissue infections. N Engl J Med 2017;377:2253-65.

2 Madsen MB, Skrede S, Perner A, et al. Patient's characteristics and outcomes in necrotising soft-tissue infections: results from a Scandinavian, multicentre, prospective cohort study. Intensive Care Med 2019;45:1241-51.

3 Sudarsky LA, Laschinger JC, Coppa GF, et al. Improved results from a standardized approach in treating patients with necrotizing fasciitis. Ann Surg 1987;206:661-5.

4 Brandt MM, Corpron CA, Wahl WL. Necrotizing soft tissue infections: a surgical disease. Am Surg 2000;66:961-7.

5 Elliott DC, Kufera JA, Myers RA. Necrotizing soft tissue infections. risk factors for mortality and strategies for management. Ann Surg 1996;224:672-83.

6 Stamenkovic I, Lew PD. Early recognition of potentially fatal necrotizing fasciitis. The use of frozen-section biopsy. N Engl J Med 1984;310:1689-93.

7 Boyer A, Vargas F, Coste F, et al. Influence of surgical treatment timing on mortality from necrotizing soft tissue infections requiring intensive care management. Intensive Care Med 2009;35:847-53.

8 Wong $\mathrm{C}-\mathrm{H}$, Chang $\mathrm{H}-\mathrm{C}$, Pasupathy $\mathrm{S}$, et al. Necrotizing fasciitis: clinical presentation, microbiology, and determinants of mortality. $J$ Bone Joint Surg Am 2003;85:1454-60.

9 Majeski JA, Alexander JW, diagnosis E. Early diagnosis, nutritional support, and immediate extensive debridement improve survival in necrotizing fasciitis. Am J Surg 1983;145:784-7.

10 Majeski J, Majeski E. Necrotizing fasciitis: improved survival with early recognition by tissue biopsy and aggressive surgical treatment. South Med J 1997;90:1065-8.

11 Freischlag JA, Ajalat G, Busuttil RW. Treatment of necrotizing soft tissue infections. The need for a new approach. Am J Surg 1985;149:751-5.

12 Devaney B, Frawley G, Frawley L, et al. Necrotising soft tissue infections: the effect of hyperbaric oxygen on mortality. Anaesth Intensive Care 2015;43:685-92.

13 Shaw JJ, Psoinos C, Emhoff TA, et al. Not just full of hot air: hyperbaric oxygen therapy increases survival in cases of necrotizing soft tissue infections. Surg Infect 2014;15:328-35.

14 Soh CR, Pietrobon R, Freiberger JJ, et al. Hyperbaric oxygen therapy in necrotising soft tissue infections: a study of patients in the United States nationwide inpatient sample. Intensive Care Med 2012;38:1143-51.

15 Bennett MH, Millar I, M.H. BD. L, M.H. B, Levett D, et al. Adjunctive hyperbaric oxygen for necrotizing fasciitis. Cochrane Database Syst Rev 2015;1:CD007937.

16 Sartelli M, Guirao X, Hardcastle TC, et al. 2018 WSES/SIS-E consensus conference: recommendations for the management of skin and soft-tissue infections. World J Emerg Surg 2018;13:1-24.

17 Stevens DL, Bisno AL, Chambers HF, et al. Executive summary: practice guidelines for the diagnosis and management of skin and soft tissue infections: 2014 update by the infectious diseases Society of America. Clin Infect Dis 2014;59:147-59.

18 Audureau E, Hua C, de Prost N, et al. Mortality of necrotizing fasciitis: relative influence of individual and hospital-level factors, a nationwide multilevel study, France, 2007-12. Br J Dermatol 2017;177:1575-82. 
19 Schmidt M, Schmidt SAJ, Sandegaard JL, et al. The Danish national patient registry: a review of content, data quality, and research potential. Clin Epidemiol 2015;7:449-90.

20 Schmidt M, Pedersen L, Sørensen HT. The Danish civil registration system as a tool in epidemiology. Eur J Epidemiol 2014;29:541-9.

21 Helweg-Larsen K. The Danish register of causes of death. Scand J Public Health 2011;39:26-9.

22 Charlson ME, Pompei P, Ales KL, et al. A new method of classifying prognostic comorbidity in longitudinal studies: development and validation. J Chronic Dis 1987;40:373-83.

23 Quan H, Li B, Couris CM, et al. Updating and validating the Charlson comorbidity index and score for risk adjustment in hospital discharge Abstracts using data from 6 countries. Am J Epidemiol 2011;173:676-82.

24 Benchimol El, Smeeth L, Guttmann A, et al. The reporting of studies conducted using observational Routinely-collected health data (record) statement. PLoS Med 2015;12:e1001885.

25 Khamnuan P, Chongruksut W, Jearwattanakanok K, et al. Necrotizing fasciitis: epidemiology and clinical predictors for amputation. Int $J$ Gen Med 2015;8:195-202.

26 Das DK, Baker MG, Venugopal K. Increasing incidence of necrotizing fasciitis in New Zealand: a nationwide study over the period 1990 to 2006. J Infect 2011:63:429-33.

27 Naseer U, Steinbakk M, Blystad H, et al. Epidemiology of invasive group A streptococcal infections in Norway 2010-2014: a retrospective cohort study. Eur $\mathrm{J}$ Clin Microbiol Infect Dis 2016;35:1639-48.

28 Dixon B. Fasciitis continues to surprise. Lancet Infect Dis 2008;8:279.

29 Soltani AM, Best MJ, Francis CS, et al. Trends in the incidence and treatment of necrotizing soft tissue infections: an analysis of the National hospital discharge survey. J Burn Care Res 2014;35:449-54.

30 Fernando SM, Tran A, Cheng W, et al. Necrotizing soft tissue infection: diagnostic accuracy of physical examination, imaging, and LRINEC score: a systematic review and meta-analysis. Ann Surg 2019;269:58-65.

31 Levenson RB, Singh AK, Novelline RA. Fournier gangrene: role of imaging. Radiographics 2008;28:519-28.

32 Nougué H, Le Maho A-L, Boudiaf M, et al. Clinical and imaging factors associated with severe complications of cervical necrotizing fasciitis. Intensive Care Med 2015;41:1256-63.

33 Wong C-H, Khin L-W, Heng K-S, et al. The LRINEC (laboratory risk indicator for necrotizing fasciitis) score: a tool for distinguishing necrotizing fasciitis from other soft tissue infections. Crit Care Med 2004;32:1535-41.

34 Bechar J, Sepehripour S, Hardwicke J, et al. Laboratory risk indicator for necrotising fasciitis (LRINEC) score for the assessment of early necrotising fasciitis: a systematic review of the literature. Ann $R$ Coll Surg Engl 2017;99:341-6.

35 Hansen MB, Rasmussen LS, Svensson M, et al. Association between cytokine response, the LRINEC score and outcome in patients with necrotising soft tissue infection: a multicentre, prospective study. Sci Rep 2017;7:42179.

36 Lauridsen MD, Gammelager H, Schmidt M, et al. Positive predictive value of international classification of diseases, 10th revision, diagnosis codes for cardiogenic, hypovolemic, and septic shock in the Danish national patient registry. BMC Med Res Methodol 2015;15:23.

37 Stevenson EK, Rubenstein AR, Radin GT, et al. Two decades of mortality trends among patients with severe sepsis: a comparative meta-analysis*. Crit Care Med 2014;42:625-31.

38 Rudd KE, Johnson SC, Agesa KM, et al. Global, regional, and national sepsis incidence and mortality, 1990 - 2017: analysis for the global burden of disease study. Lancet 2020;6736:1-12.

39 Sperling C, Noer MC, Christensen IJ, et al. Comorbidity is an independent prognostic factor for the survival of ovarian cancer: a Danish register-based cohort study from a clinical database. Gynecol Oncol 2013;129:97-102.

40 Raedkjaer M, Maretty-Kongstad K, Baad-Hansen T, et al. The impact of comorbidity on mortality in Danish sarcoma patients from 20002013: a nationwide population-based multicentre study. PLoS One 2018:13:e0198933.

41 Cronin-Fenton DP, Nørgaard M, Jacobsen J, et al. Comorbidity and survival of Danish breast cancer patients from 1995 to 2005. Br J Cancer 2007;96:1462-8.

42 Stavem K, Hoel H, Skjaker SA, et al. Charlson comorbidity index derived from chart review or administrative data: agreement and prediction of mortality in intensive care patients. Clin Epidemiol 2017;9:311-20.

43 Quan H, Sundararajan V, Halfon P, et al. Coding algorithms for defining comorbidities in ICD-9-CM and ICD-10 administrative data. Med Care 2005;43:1130-9.

44 Thygesen SK, Christiansen CF, Christensen S, et al. The predictive value of ICD-10 diagnostic coding used to assess Charlson comorbidity index conditions in the population-based Danish national registry of patients. BMC Med Res Methodol 2011;11:83.

45 Ingraham AM, Jung HS, Liepert AE, et al. Effect of transfer status on outcomes for necrotizing soft tissue infections. J Surg Res 2017;220:372-8.

46 Proud D, Bruscino Raiola F, Holden D, et al. Are we getting necrotizing soft tissue infections right? A 10 -year review. ANZ J Surg 2014;84:468-72.

47 Mathieu D, Marroni A, Kot J. Tenth European consensus conference on hyperbaric medicine: recommendations for accepted and nonaccepted clinical indications and practice of hyperbaric oxygen treatment. Diving Hyperb Med 2017;47:131-2.

48 Bakker D. Clostridial myonecrosis (gas gangrene). In: Weaver LK, ed. Hyperbaric oxygen therapy indications. Best Publishing Company, 2014: 114-25.

49 Jacoby I. Necrotizing soft tissue infections. Hyperb Oxyg Ther Indic 2014:39:739-52. 